\title{
Proficiency and Confidence Levels of English Language Students in Relation to ASEAN Integration's Regional Lingua Franca
}

\author{
Joyce Ann M. Tolentino*, Elizabeth W. Santos \\ College of Education, Don Honorio Ventura State University, Philippines \\ Received September 28, 2020; Revised November 11, 2020; Accepted November 29, 2020
}

Cite This Paper in the following Citation Styles

(a): [1] Joyce Ann M. Tolentino, Elizabeth W. Santos, "Proficiency and Confidence Levels of English Language Students in Relation to ASEAN Integration's Regional Lingua Franca," Universal Journal of Educational Research, Vol. 8, No. 12A, pp. 7494 - 7499, 2020. DOI: 10.13189/ujer.2020.082533.

(b): Joyce Ann M. Tolentino, Elizabeth W. Santos (2020). Proficiency and Confidence Levels of English Language Students in Relation to ASEAN Integration's Regional Lingua Franca. Universal Journal of Educational Research, 8(12A), 7494 - 7499. DOI: 10.13189/ujer.2020.082533.

Copyright $\mathrm{C} 2020$ by authors, all rights reserved. Authors agree that this article remains permanently open access under the terms of the Creative Commons Attribution License 4.0 International License

\begin{abstract}
The sole working language of ASEAN region is English. The Philippines as one of the members of ASEAN should adhere to this; that is why the Philippine government in coordination with the Philippine higher education mandates English as the medium of instruction in the tertiary level. This study was conducted to the graduating students of the Bachelor of Secondary Education majoring in English in a Philippine state university during the academic year 2015 to 2016 to determine their proficiency and confidence levels in English as regional lingua franca of Southeast Asia. Results showed that the respondents were confident in terms of their speaking skills, but they were not proficient in terms of their reading and writing skills. It was also found out that there was a significant difference in speaking when grouped according to the level of proficiency in reading. However, no significant difference was found in speaking when grouped according to the level of proficiency in writing. To prepare students to face the world of work and the ASEAN Integration, it was recommended that a more rigid admission policy be stipulated in the state university where this study was conducted. The university must be stricter and more cautious in selecting its students, especially those who apply for a specific area of specialization.
\end{abstract}

Keywords Proficiency Level, Confidence Level, English, Regional Lingua Franca, ASEAN Integration

\section{Introduction}

The ASEAN Economic Community (AEC) shall be the end point of the integration of the 10-member countries comprising the ASEAN region, including the Philippines. As AEC draws closer to becoming a reality, Cambodian Minister of Foreign Affairs Hor Namhong announced that the only means of communication among the ASEAN people is English [1]. Before this announcement, it has been included in Article 34 of the ASEAN Charter [2] that English serves as the working language of ASEAN.

As a result, employing English in communicating with the ASEAN community has become an important issue. The ASEAN members are mandated to encourage English language usage and to improve English language communication since it is the ASEAN community's regional lingua franca.

By definition, lingua franca is a language that is customarily spoken by individuals who have varying mother tongues to make communication possible among them [3]. English as a lingua franca is a way of conversing in English between individuals with dissimilar native languages [4]. In the ASEAN community, for instance, Filipinos, Malaysians, and Cambodians must utilize English as their lingua franca - the language 
common to them-to make verbal exchange of information possible among them.

Thus, the use of English in diverse or multilingual environments has also been one of the crucial facets in making learners ready in terms of life and career skills in the 21st Century [5].

Woodhead, who founded the Center for Professional Assessment Thailand, remarked that "ASEAN needs to make some standards for professional workers especially related to their English skills" [6].

With this proposition, Woodhead underscored the ASEAN Community's "three pillars: politics and security, social and culture, and economy" which will challenge its people to utilize English as their communication channel [6].

The utilization of English as the means of instruction shows that English is also a language that is accessible not only to socio-economic powers, but to political influences as well. It is an advantage to use English as ASEAN's regional lingua franca because it implies shared characteristics or attributes among individuals belonging to different native languages (L1); it welcomes local variations of English and some features of the first language (for instance accent); and it encourages multilingual English speakers to have a sense of ownership of the English language [7]. Accordingly, English will possibly help in uniting the ASEAN members with the recognition that there exists a common ground between them; that is, the English language that will bind them in the creation of a stronger ASEAN regional community.

There is no denying that English has turned into a global lingua franca. The Philippine government acknowledges that having a good grasp of the English language is essential for university graduates. Since English teaching is significant in Philippine higher education, especially in the state university where the study was conducted, it is necessary that student teachers must be equipped with the necessary English skills. It is expected from universities to prepare student teachers in dealing with the challenges brought about by the fast-evolving world. To accomplish this, universities must empower their student teachers by nurturing them with the necessary knowledge, skills, and proper attitude to carry out the tasks expected from them. For instance, Masedah [8] noted that student teachers often need assistance in language use, specifically in integrating it in their practicum. In the Philippines, the English proficiency of students and their confidence in speaking the English language are some of the challenges that confront the higher education.

According to Zhang [9], the motto "Think globally, act locally" of the United Nations pertains to every student being educated as an international learner and a global citizen who aims to compete globally. Hence, a Filipino graduating student must not only be equipped with practical skills but also a universal language that will enable the student to compete in an integrated or diversified economic region like ASEAN.

More than one's capability to use an acquired language in daily conversation with other people, language proficiency pertains to the utilization of a language, English for instance, for educational and pedagogical purposes [10]. Fluency and competence in language are normally associated since fluency is defined as "a complex cognitive skill that requires learners to use linguistic knowledge in a cognitively fluent way in speech processing" [11]. However, there are also native speakers of the English language who are regarded as fluent but not necessarily proficient. In this study, English proficiency is associated with one's skill in speaking, reading, and writing using English as the communication tool. To be proficient, one must be adept in these three macro skills. Since English is a global language, one has to speak in English to be able to communicate to people in other countries.

In the article "English proficiency as a competitive edge" by Hernandez [12], he mentioned that the Department of Education (DepEd) itself is aware that the earlier generations of the Filipinos have edge in terms of their proficiency in English. However, this changed as the generations of today find it difficult to express themselves not only in English, but in their own dialect as well. Forbes magazine's contributing writer Rapoza, as cited by Hernandez, mentioned a Mckinsey \& Company study that showed lack of English skills as the foremost reason why only 13 percent of graduates from developing countries are being hired in top rank organizations in spite of the fact that the Philippines ranked third in the English proficiency index in Asia [13].

Filipinos are known for being English proficient. However, escalating competitions with deteriorating mastery of some college graduates gradually destroyed this edge. For instance, IDP Education Pty. Ltd. Philippines recently took a language examination which revealed that the country has lost its position as the top among all the English-speaking countries in Asia. This can be attributed to students' lack of enthusiasm to boost their skill in the use of the English language [14].

Confidence is the general belief in being able to converse in the second language, English in particular, in an "adaptive and efficient manner" [15]. The level of confidence of each individual differs in every situation. An individual tends to be extremely confident in a familiar environment. However, when confronted with a challenging setting, the person's level of confidence may weaken.

Rickheit and Strohner [16] claimed that students' confidence is one of the aspects that requires improvement in language learning, specifically in speaking. Additionally, they stated that confidence of students can be nurtured by making them experience success, by 
offering them with encouragement, and by lowering their level of anxiety. They also reasoned that a lot of people seem to look very contented and successful once they managed to acquire at least the advance fluent levels of proficiency.

In this study, the researchers sought to determine the proficiency and confidence levels of graduating English major students in a Philippine state university for the academic year 2015-2016 in relation to the ASEAN Integration's regional lingua franca, which is also English. Tracing the performance in the Licensure Examination for Teachers (LET) of the graduates of Bachelor of Secondary Education (BSEd) major in English, there is an improvement in the graduates' performance rating since 2013. In September 2013, the LET passing rate of the BSEd major in English is 64.42 percent. In August 2014, it went up to 80.85 percent. In September 2015, it exceeded the previous year's performance by almost 15 percent, obtaining a percentage of 95.35. However, it is obvious that the graduates' good performance rating for two consecutive years was not sustained when in the licensure exam in September 2016, the percentage rate dropped by 18.43 , obtaining a passing rate of 76.92 percent.

Included in the vision and mission of this Philippine state university is to produce globally competitive graduates. Therefore, it is but necessary that the university remains committed to its mission by turning its graduates not only as experts in their fields but rather, communicatively competent as well.

Communicative competence involves a complex structure, as it can be related to terminologies such as effectiveness and appropriateness. While effectiveness outlines the result of being communicatively competent, appropriateness, on the other hand, links it to the actual social interaction [16].

To be communicatively competent means to be able to use the English language correctly, specifically when it comes to the macro skills, such as speaking, reading, and writing. Communication is not only limited to the actual interaction or conversation with another individual or group of individuals. Individuals communicate not only through speaking, but through reading and writing as well.

\section{Objectives}

The study aimed to determine the proficiency and confidence levels of the graduating students in a Philippine state university, for the academic year 2015-2016, in English as regional lingua franca of Southeast Asia. Specifically, it determined the respondents' proficiency level in reference to their reading and writing skills, and described the respondents' confidence level in reference to their speaking skills. This study also determined the significant difference of the respondents' confidence level in speaking when grouped according to their level of proficiency in reading, and when grouped according to their level of proficiency in writing. The results were assessed to find out the readiness of the respondents towards the ASEAN Integration's regional lingua franca.

\section{Methods}

Descriptive quantitative method was utilized in the conduct of this study. According to Hopkins [17], this type of research intends to find out the relationship between independent and dependent variables. It is also known as observational type of study since the respondents are not being controlled or manipulated but are observed.

The respondents were the 95 graduating students of the Bachelor of Secondary Education majoring in English in a Philippine state university during the academic year 2015 to 2016. The examinations were administered by the researchers. Among the 95 respondents surveyed, 61 of them answered and returned the examination. Since the respondents were in their Pre-Service Program during the course of the study, 64 percent response rate was gathered.

Proficiency is operationally defined as the state of being adept at written English usage, specifically reading and writing. In measuring the proficiency level of the respondents, a sample International English Language Testing System (IELTS) General Training exam was adopted by the researchers. To be categorized as proficient, the respondents must not get a score lower than 75 percent of the total correct answers. Since the respondents were graduating English major students, the passing score was set to be above the average.

Confidence is operationally defined as the ability to utilize spoken English effectively. The confidence level of the respondents was described through their teaching demonstrations. The Pre-Service Teacher Demonstration Teaching Observation Guide of the state university's College of Education was adapted by the researchers in describing the respondents' confidence level. The standard was set to not lower than 90 percent, since the respondents were expected to have acquired a good grasp of the English language.

T-test independent was used to determine the significant difference of the respondents' confidence level in reference to speaking when grouped according to their level of proficiency in reading, and when grouped according to their level of proficiency in writing. This tool was used to determine whether the means of two groups are statistically different or not [18].

The readiness of the respondents was assessed based on their proficiency in both reading and writing, and on their confidence in speaking. Therefore, in order for the respondents to be categorized as ready towards the ASEAN Integration's regional lingua franca, which is 
English, they must be both proficient in reading and writing as well as confident in speaking.

\section{Results and Discussion}

Hymes, who presented the idea of communicative competence in the 1960s, pointed out that one's grammar know-how is not only the basis for communication, particularly speaking [16]. Societies believe that effective communication has a lot of limitations, one of the most vital ones is the skill of the interlocutors.

According to Holtgraves [16], "language use is intentional behavior". The basic linguistic competencies required in speaking cover the phonological, morphological, and syntactic competencies. However, a speaker's main goal is to let the listener know of his or her message through his or her spoken language. In order to accomplish this, the speaker must convert these competencies into words which must be easily recognized and understood by the listener.

Individuals who speak their mother tongue exude confidence in the manner they deliver the language. However, speaking in a foreign language, specifically English, entails a lot of considerations. This is true to non-speakers of the English language, especially to the Filipinos. They either get too intimidated by the language that they tend to shy away from it, or they get too absorbed in it that they use it as if it is their first language. Confidence, in this case, should be taken into consideration. Although confidence cannot be defined easily, it generally portrays a mental attitude that gives emphasis on an individual's trust on his or her capabilities. A form of self-reliance, it can be associated with motivation and self-esteem. To be confident in using the English language would mean to be able to utilize the language in various social and transactional interactions, and with different individuals from various professions and cultural upbringings [19].

Improving one's vocabulary skills is a contributory factor in enhancing one's proficiency in reading. According to the National Assessment of Educational Progress (NAEP), the active and complex course of reading encompasses "understanding written text; developing and interpreting meaning; and using meaning as appropriate to type of text, purpose, and situation". The National Reading Panel (NRP), on the other hand, identified "phonemic awareness, phonics, reading fluency, and reading comprehension" as crucial to an individual's reading development [20]. Reading proficiency, as a whole, demands skills that are interrelated, such as language and communication.

Table 1 shows that 43 out of the 61 respondents, which is equivalent to 70.5 percent of the total respondents, are confident in speaking. Three from these respondents who are confident in speaking are also proficient in reading. It can also be noted that 58 respondents, with a percentage of 95.1, are not proficient in reading.

Table 1. Proficiency in Reading and Confidence in Speaking

\begin{tabular}{|c|c|c|c|}
\hline \multirow{2}{*}{$\begin{array}{c}\text { Confidence } \\
\text { in Speaking }\end{array}$} & \multicolumn{2}{|c|}{ Proficiency in Reading } & \multirow{2}{*}{ Total } \\
\cline { 2 - 3 } & Proficient & Not Proficient & \\
\hline \multirow{3}{*}{ Confident } & 3 & 40 & 43 \\
\cline { 2 - 3 } & $4.9 \%$ & $65.6 \%$ & $70.5 \%$ \\
\hline \multirow{2}{*}{$\begin{array}{c}\text { Not } \\
\text { Confident }\end{array}$} & 0 & 18 & 18 \\
\cline { 2 - 4 } & $.0 \%$ & $29.5 \%$ & $29.5 \%$ \\
\hline \multirow{3}{*}{ Total } & 3 & 58 & 61 \\
\cline { 2 - 4 } & $4.9 \%$ & $95.1 \%$ & $100.0 \%$ \\
\hline
\end{tabular}

Proficiency in writing means being able to observe proper and effective usage of grammar, diction, punctuation, spelling, and syntax. Students must be able to express basic ideas and concepts in an organized and a coherent manner. Since the respondents were graduating students specialized in English, it was expected that they have fully developed, if not gained mastery, of their writing skills in English.

As shown on Table 2, there are 15 respondents out of the 61 who are proficient in writing. Twelve from these 15 are also confident in speaking, while the remaining three are not confident. Based on the results, it is also evident that a larger percentage of 75.4 of the total respondents fall under the not proficient category in writing.

Table 2. Proficiency in Writing and Confidence in Speaking

\begin{tabular}{|c|c|c|c|}
\hline \multirow{2}{*}{$\begin{array}{c}\text { Confidence in } \\
\text { Speaking }\end{array}$} & \multicolumn{2}{|c|}{ Proficiency in Writing } & \multirow{2}{*}{ Total } \\
\cline { 2 - 3 } Confident & Proficient & Not Proficient & \\
\cline { 2 - 3 } & 12 & 31 & 43 \\
\hline \multirow{2}{*}{ Not Confident } & $19.7 \%$ & $50.8 \%$ & $70.5 \%$ \\
\cline { 2 - 4 } & 3 & 15 & 18 \\
\hline \multirow{2}{*}{ Total } & $4.9 \%$ & $24.6 \%$ & $29.5 \%$ \\
\cline { 2 - 4 } & $24.6 \%$ & 46 & 61 \\
\hline
\end{tabular}

In the study of Mart [21], it was found out that there is a significant relationship between these two macro skills-reading and speaking; that individuals whose reading vocabularies are extensive are more likely to enhance their speaking vocabularies. Having wide vocabulary is necessary to improve one's speaking skills.

Based on the t-value of 7.021, Table 3 illustrates that there is a significant difference in speaking when grouped according to the level of proficiency in reading. Three respondents who are confident in speaking are also proficient in reading. Looking at the results, it can be said that someone who is proficient in reading is also confident in speaking. 
Table 3. Test of Difference in Speaking when Grouped According to the Level of Proficiency in Reading

\begin{tabular}{|c|c|c|c|c|c|}
\hline Reading & $\mathrm{N}$ & Mean in Speaking & Std. Deviation & t-value & Verbal Interpretation \\
\hline Proficient & 3 & 95.33 & .577 & \multirow{2}{*}{7.021} & $\begin{array}{c}\text { There is a significant } \\
\text { difference at } .01\end{array}$ \\
\hline Not Proficient & 58 & 89.93 & 5.281 & & \\
\hline
\end{tabular}

Table 4. Test of Difference in Speaking when Grouped According to the Level of Proficiency in Writing

\begin{tabular}{|c|c|c|c|c|c|}
\hline Writing & $\mathrm{N}$ & Mean in Speaking & Std. Deviation & t-value & Verbal Interpretation \\
\hline Proficient & 15 & 90.87 & 5.330 & \multirow{2}{*}{0.561} & $\begin{array}{c}\text { There is no significant } \\
\text { difference at } .05\end{array}$ \\
\hline Not Proficient & 46 & 89.98 & 5.306 & & \\
\hline
\end{tabular}

With a t-value of 0.561 , Table 4 reveals that there is no significant difference in speaking when grouped according to the level of proficiency in writing. This means that it does not follow when the respondents are confident in speaking, they are also proficient in writing.

In every field of communication both locally and globally, English has become the medium of communication [22]. The two macro skills-reading and writing - are interdependent; in reading, the symbols are recognized either mentally or verbally. In writing, these symbols are materialized and concretized through visible marks. The reader has to decipher such codes and assign their roles in the construction of a sentence.

In assessing the readiness of the respondents towards the ASEAN Integration's regional lingua franca, which is English, the researchers categorized the respondents into ready and not ready. Those who are ready must not only be confident in speaking, but they must also be proficient in both reading and writing. Therefore, in order to be considered as ready, the respondents must be communicatively competent.

Based on the results on Table 5, only one respondent is confident in speaking and proficient in both reading and writing. A percentage of 98.36 of the graduating English major students are not ready towards the ASEAN Integration's regional lingua franca, which is English - their supposed to be area of specialization.

Table 5. Assessment on the Readiness of the Respondents Towards the ASEAN Integration's Regional Lingua Franca

\begin{tabular}{|c|c|c|}
\hline Proficient in Reading and & Ready & Not Ready \\
\cline { 2 - 3 } Writing & 1 & 60 \\
Confident in Speaking & $1.64 \%$ & $98.36 \%$ \\
\hline
\end{tabular}

\section{Conclusions}

The purpose of this study was to determine the proficiency and confidence levels of a Philippine state university's graduating English major students for the academic year 2015-2016 in relation to English as regional lingua franca of Southeast Asia. The results show that 70.5 percent of the respondents are confident when it comes to their skills in speaking the English language. However, when it comes to their reading skills, 95.1 percent are not proficient. This is also the case in reference to the writing skills of the respondents as 75.4 percent of the graduating English major students belong to the not proficient category.

It is important to note, though, that three of the respondents who are confident in speaking are also proficient in reading. It only proves that there is, indeed, a significant difference in speaking when grouped according to the level of proficiency in reading. This is consistent with the results of the study of Mart [21], wherein individuals whose reading vocabularies are extensive are more likely to enhance their speaking vocabularies. This is not the case, however, when it comes to writing as the results of this study show that there is no significant difference in speaking when grouped according to the level of proficiency in writing.

The researchers also assessed the readiness of the graduating English major students towards English, which is the regional lingua franca of the ASEAN Integration. The result shows that only one respondent is confident in speaking and proficient in both reading and writing. Thus, among the 61 who managed to answer the exams administered by the researchers, only one is ready to face the world of work and the ASEAN Integration based on the results of this study.

In this light, it is recommended that a more rigid admission policy be stipulated in the state university where this study was conducted. In this case, the College of Education must be stricter and more cautious in selecting its students, especially those who apply for a specific area of specialization. Following this admission policy is a retention policy that must be followed religiously. Students who are unable to maintain the required grade in their chosen program and area of specialization must be given options. Therefore, this retention policy must be designed in such a way that is beneficial to both the college and the students. A mentoring session among teachers is also fitting to make their instruction more effective. This must be tied up with monitoring. It is not enough that teachers mentor their peers, but there should be continuous monitoring of their peers' progress. This can also be extended among the students. To prevent students from falling behind their courses, teachers must be vigilant enough to monitor the progress of their students as well as address their concerns. 
The results of this study will serve as a basis for an intervention program - a qualifying exam for applicants who want to specialize in the English language. Apart from the entrance exam that the Admissions Office requires to each applicant, another specialized qualifying exam must be taken by those who want to enroll in a program with specific specialization. This exam will thoroughly select qualified applicants in high hopes of producing topnotchers in the succeeding Philippine Licensure Examination for Teachers.

\section{Acknowledgments}

This research was supported by the Research and Development Services Office of the Don Honorio Ventura State University, Philippines.

\section{REFERENCES}

[1] Suy, P., "English Key to Success in Asean Integration", Khmer Times, http://www.khmertimeskh.com/news/15168/ ---english-key-to-success-in-asean-integration---/ (accessed May 2, 2018).

[2] “The ASEAN Charter", ASEAN, asean.org/wp-content/upl oads/images/.../ASEAN-Charter.pdf (accessed April 12, 2018).

[3] Wardhaugh, R., "Pidgins and Creoles," in An Introduction to Sociolinguistics, 6th ed, Wiley-Blackwell, 2010, pp. 55.

[4] Seidlhofer, B., "English as a lingua franca," ELT Journal, vol. 59, no. 4, pp. 339-341., 2005. DOI: 10.1093/elt/cci064

[5] Trilling, B. \& Fadel, C., "Learning and Innovation Skills: Learning to Create Together" in 21st Century Skills: Learning for life in Our Times, Jossey-Bass, 2009, pp. 54-56.

[6] Priyambodo, RH (ed.), "Language as the most important key towards ASEAN community", Antaranews.com, https://en.antaranews.com/news/76521/language-as-the-mo st-important-key-towards-asean-community (accessed May 2, 2018).

[7] Nomnian, S. "English as the ASEAN lingua franca in Thai Higher Education," Veridian E-Journal, vol. 7, no. 4, pp. 77-78, 2014, https://he02.tci-thaijo.org/index.php/VeridianE-Journal/article/download/27215/23134

[8] Masadeh, T., "Opportunities and Barriers of Practicum from the Perspectives of English Language Student Teachers," Universal Journal of Educational Research, vol. 5, no. 6, pp. 1059-1071., 2017. DOI: 10.13189/ujer.2017.050620

[9] Yan Zhang, C., "The Rise of Glocal Education: ASEAN Countries", TOPUNIVERSITIES, https://www.topuniversit ies.com/where-to-study/region/asia/rise-glocal-education-as ean-countries (accessed May 2, 2018).
[10] Merwe, M., "Background, Formulation of the Problem and Aims of the Study" in English Language Proficiency of Non-English Speaking Learners in the Foundation Phase of an English Medium School: Challenges and Strategies, DSpace Repository, http://ir.cut.ac.za/bitstream/handle/114 62/677/Van\%20der\%20Merwe\%2C\%20Margaretha\%20M aria.pdf? sequence $=1 \&$ isAllowed $=\mathrm{y}$ (accessed November 04, 2020)

[11] Mora, J., \& Valls-Ferrer, M., "Oral Fluency, Accuracy, and Complexity in Formal Instruction and Study Abroad Learning Contexts," TESOL Quarterly, vol. 46, no. 4, pp. 610-641, 2012, http://www.jstor.org.dlsu.idm.oclc.org/stabl e/43267882

[12] Hernandez, B., "English proficiency as a competitive edge", INQUIRER.NET, http://opinion.inquirer.net/86602/english-proficiency-as-a-c ompetitive-edge\#ixzz4mQMYG7FB (accessed April 12, 2018).

[13] "EF English Proficiency Index: Asia”, EF Education First, http://www.ef.com//epi/regions/asia/ (accessed March 18, 2018).

[14] Marcelo, P., "English Proficiency is Key to Landing a Job", Planet Philippines, http://planetphilippines.com/currentaffairs/english-proficiency-is-key-to-landing-a-job/ (accessed Jan. 17, 2018).

[15] Khajavy, G., Ghonsooly, B., Fatemi, A., \& Choi, C., "Willingness to Communicate in English: A Microsystem Model in the Iranian EFL Classroom Context," TESOL Quarterly, vol. 50, no. 1, pp. 154-180, 2016, http://www.jstor.org.dlsu.idm.oclc.org/stable/43893807

[16] Rickheit, G. \& Strohner, H. (eds.), "The concept of communicative competence" in Handbook of Communication Competence, Mouton de Gruyter, 2008, pp. $15-26$.

[17] Hopkins, W., "Quantitative Research Design”, sportsci.org, http://www.sportsci.org/jour/0001/wghdesign.html (accessed Jan. 17, 2018).

[18] Trochim, W., “The T-Test”, Conjoint.ly, http://www.socialr esearchmethods.net/kb/stat_t.php (accessed Feb. 20, 2018).

[19] Yates, L. \& Chisari, M., "Fact Sheet 1: Building Confidence in the Classroom and Beyond", Anyflip, http://anyflip.com/zljp/evjn (accessed Jan. 17, 2018).

[20] Connors-Tadros, L., "Definitions and Approaches to Measuring Reading Proficiency", CEELO Center on Enhancing Early Learning Outcomes, http://ceelo.org/wp-c ontent/uploads/2014/05/ceelo_fast_fact_reading_proficienc y.pdf (accessed April 12, 2018).

[21] Mart, C. T., "Developing Speaking Skills through Reading," International Journal of English Linguistics, vol. 2, no. 6, pp. 91-96, 2012. DOI: 10.5539/ijel.v2n6p91

[22] Parupalli, S.R., "The Role of English as a Global Language," Research Journal of English, vol. 4, no. 1, pp. 65-79, 2019. https://www.researchgate.net/profile/Parupalli_Rao/publica tion $/ 334282978$ 